\title{
AC 2010-2298: EARLY UNDERGRADUATE RESEARCH AT THE UNIVERSITY OF SOUTHERN INDIANA
}

Zane Mitchell, University of Southern Indiana

Engineering Department Chair

Marco Lara Gracia, University of Southern Indiana

Assistant Professor

Ronald Diersing, University of Southern Indiana

Assistant Professor

Glen Kissel, University of Southern Indiana

Associate Professor 


\title{
Early Undergraduate Research at the University of Southern Indiana
}

\begin{abstract}
The University of Southern Indiana (USI) is a participant in a National Science Foundation grant project to expose talented freshman STEM majors to research through a summer program at the completion of their freshman year with one-on-one mentoring with faculty members for that summer, their sophomore year, and the summer after their sophomore year. The first offering of this program occurred during summer of 2009 with three engineering faculty members selected to provide guidance to four freshmen. The students had the opportunity to not only work on their projects, but also to learn about projects that other students and faculty were doing in the basic sciences. This paper will present the early results of this program, both for the summer portion and the on-going mentoring relationships. Assessment methods include student performance in their sophomore classes and qualitative assessment of student attitudes. A departmental strategy for continuation of this program after expiration of the grant will also be explored.
\end{abstract}

\section{Introduction}

At the University of Southern Indiana (USI), and throughout the nation, post-secondary science, technology, engineering, and math (STEM) programs are having difficulty with the recruiting and retention of students. The National Science Foundation (NSF) created the STEM Talent Expansion Program (STEP) grants to help devise ways to address these issues. USI received a grant from the NSF in 2008 to take a 4-pronged approach towards increasing the number of STEM graduates in our region. The funds are being used to engage STEM majors in early undergraduate research, to provide more intensive academic advising to at-risk STEM majors early in their undergraduate education, to improve K-12 STEM outreach programs in the region, and to provide better training for K-16 teachers in the STEM fields.

It is particularly important to USI that we increase our retention and graduation rates within our STEM programs. Data indicate that only 13\% of STEM freshmen actually graduate with STEM degrees from our institution by the 6 year point. Roughly 50\% of incoming STEM freshmen have transferred out of the STEM programs by the end of their freshman year. A further $20 \%$ of those incoming STEM majors have transferred out by the end of their sophomore year.

This paper will focus on the initial successes of the early undergraduate research program in the Engineering Department. The early undergraduate research program provides an immersion into STEM research for selected volunteers from the freshman population majoring in STEM programs. Eligibility criteria for the students are that they have a minimum of a 2.75 cumulative GPA on a 4.0 scale, be full time students who have taken at least 12 semester hours in their first and second semesters, have taken at least one STEM course, and have good academic and disciplinary standing at the university. Interested students review research proposals that are posted on-line by potential faculty mentors. They apply for the program through the Pott College of Science and Engineering. Applications must include a letter of recommendation from a faculty member. 
Faculty members interested in being mentors for the early undergraduate research program must also submit applications to the college. Applications include a description of the research project they would like to undertake. They must be willing to make the commitment for participating in the program 2 years in a row during the summer for 8 weeks. They must also be willing to mentor students during the academic year between those two summers. Although they are provided with a stipend for program participation in the summers, they are not provided a stipend for participation during the normal academic year. Faculty members are not permitted to draw funds from other stipends/fellowships during the 8-week summer period. Some release time is available during the academic year for faculty participants. There is also a small equipment/materials budget available for each research project.

If selected to participate in the early undergraduate research program, students must commit to participate for 8 weeks two summers in a row plus the academic year in between those two summers. Students are given a stipend plus room and board during the summer sessions. Students must maintain a 2.75 cumulative GPA in order to continue into the second summer of the program. They are expected to meet with their faculty mentor on a daily basis during the 8week period. The faculty mentor provides any necessary background instruction and then gets the student involved in his or her research. The goal is for hands-on research to begin the first week of the program. Typically, faculty mentors work with the students until lunch time, after which the students continue research on their own. The students and mentors get together as a group each Friday during the 8 week session. At these group meetings, students present the progress of their research and have the opportunity to learn about the progress others are making. At the conclusion of the 8 weeks, students are required to make a more in-depth presentation to a larger university audience and must complete a written report of the work accomplished.

During the academic year, students are expected to continue their research and interaction with their faculty mentor. The students are enrolled in a one semester hour research course with their mentor as their advisor. The tuition for the one semester hour is paid for out of the grant funds.

The second summer, students repeat the 8-week summer session described above. They continue their research, but must complete a more detailed final report of what they have done during the entire early undergraduate research experience. The intent of the program is that these reports will be of sufficient quality to be presented at regional or national conferences. A travel stipend is available for students whose papers are accepted for presentation.

USI offers an ABET-accredited Bachelor of Science in Engineering program with civil, electrical, industrial, and mechanical engineering emphases. The university is primarily a commuter campus with many students engaged in part-time jobs outside of school. The engineering program offers both a 4-year and a 5-year path to the Bachelor of Science degree. The 5-year path is primarily intended for those whose math skills do not permit them to succeed in calculus their first semester of enrollment.

A total of 18 students were competitively selected to participate in the first summer offering of early undergraduate research in 2009. Of these 18 , four were engineering undergraduates. Cumulative GPAs (on a 4.0 scale) for these four students ranged from 3.69 to 2.77. Two of the students selected were on the 4-year degree path, two were on the 5-year degree path. Three 
faculty members from the department agreed to participate in the program: one electrical, one mechanical, and one industrial engineer. The industrial engineering faculty member took on two of the students. The following sections will describe the research undertaken by each of these four students and provide faculty observations on the effectiveness of the program on the students.

\section{Control of Structures under Seismic and Wind Disturbances}

Structural control has been an interesting research topic of late. For example, consider the first generation benchmark control problem described in (B. F. Spencer Jr. 1998). The benchmark problem is a three story building that is subject to an earthquake disturbance. Control is used to reduce the vibration for a building under an earthquake disturbance. These disturbances can have a large impact in uncontrolled flexible structures and may even lead to a destruction of the building or bridge. By using control techniques, these vibrations can be effectively reduced. In particular cumulant control has been shown useful for structural vibration control (K. D. Pham 2004). In cumulant control, the controller wishes to minimize the mean, variance, and possibly other cumulants of a cost function. There are both linear and nonlinear approaches to using cumulant control. For the nonlinear approach, there has not been much work done on using discounted cost functions to solve an infinite time horizon control problem.

For this research project, the student examined the discounted cost infinite time horizon cumulant control problem involving three cumulants with the assistance of a faculty mentor. This project requires the student to use Hamilton-Jacobi-Bellman and Riccati equations. On top of that, the three story building application is a higher order system. This was challenging considering that the student participating in this research project was a freshman who had, as expected, just completed the first two Calculus courses and first mechanical physics course. The theoretical development was to be done using aspects of linear algebra and partial differential equations. These topics were, naturally, lacking in the student's background. However, this student was particularly strong in technical subjects and was motivated to learn new things.

Over the first two weeks of the project the student's mathematical skills were strengthened. The approach taken was to get the student involved in simulations first. By starting with simulations, the student could see results and develop an understanding of what vibrations mean. Furthermore, it got the student participating in hands-on research immediately, as opposed to being bogged down with the details of the mathematics. The student first was the given the opportunity to understand a simple one story building model and then simulate its uncontrolled response to the earthquake data history for the El Centro earthquake. To go along with this, some "lectures" were given on linear algebra and mathematical modeling of buildings. Once this was complete, the three story building was examined and simulated. While the student was permitted to spend most of the time working on the simulations, he was introduced to cumulant control at a steady pace through meetings with his faculty mentor. Doing things in this manner helped to minimize the student's apprehension of the involved HJB and Riccati equations. Once the student understood the equations, work developing the third cumulant HJB expressions was accomplished and applied to the linear system, quadratic cost results. The resulting linear controller was implemented and simulated using the one story building first. Once this was 
done, the student then applied the third cumulant controller to the three story benchmark problem before the summer research project time was complete.

At the end of the summer research project, it was clear that the student had advanced his knowledge. He was able to pick up things faster than at the beginning, in particular how to prove things and working with complex equations. Furthermore, it was mentioned by the student that he/she was excited to take differential equations and Calculus III. Even though the research problem was over, the student still wanted ideas to work on for the rest of the summer. The student learned several different things including those motivations aspects for future classes. The student was able to perform simulations on higher order control problems. Furthermore, he/she was able to take the HJB equations and find Riccati equations and a corresponding linear controller. This is paramount, as further studies of this work will be to extend the results to four cumulants and possibly other players instead of just a controller.

The program continued in the fall semester, though on a limited basis. The main goal for the semester was for the student to formalize and write a conference paper detailing the technical results from the summer. Since there wasn't as much time to do detailed research and the summer research was a combination of our work, it was important for the student to write and formalize his/her thoughts and results. The conference paper was one way of doing this. The student presented this paper at a regional IEEE conference.

The future goal of this research project is for the student to extend the results to include the fourth cumulant. This will take place in the spring semester. This work will include the student developing the HJB equations for the fourth cumulant problem, applying those results to the linear system quadratic cost case, developing Riccati equations, and determining a linear control law. The simulation application will then be done during summer 2010 when the student will have more time. Furthermore, in the summer the problem will be extended to include a game theoretic approach in which the system will include the control, but may contain another player such as a disturbance that can influence model uncertainty in the building model. These results will also be tested with the structural control benchmark problems, including tall building subject to high winds and possibly cable-stayed bridges.

\section{Simulation of Localization Phenomenon}

The research description for this project was "A motivated student is invited to participate in cutting edge research inspired by Nobel Prize winning work on the localization phenomenon. The student must be willing to learn to use the matrix programming software MATLAB to conduct Monte Carlo simulations of a one-dimensional optical system with 5,000,000 randomized layers..."

The student who was selected to participate in this research area was on the "five-year track" for USI's Bachelor of Science in Engineering (BSE) degree and had completed his freshman year by the time the research had begun. This meant that, among other courses, the student had completed College Algebra and the first semester of Calculus, plus a couple of three credit hour engineering "problem solving" courses meant as preparatory work for the "introduction to 
engineering" freshman courses in the regular BSE "four-year track" program. Because the student had not yet taken the "introduction to engineering" courses where MATLAB is taught, the student's greatest weakness was a lack of knowledge of MATLAB, which would be the key software tool for this research project.

During summer 2009, the faculty mentor met daily with the student on the research project. The beginning of the summer was devoted to teaching the student the basics of MATLAB and to introducing the research problem to the student at a level that he could understand. Fortunately students with a modest mathematics background can readily handle this research area, as long as some basic matrix algebra and MATLAB skills are acquired. Because the research only uses matrices of size $2 \times 2$, this task was manageable.

Two easily grasped mathematical concepts were the basis for the research. Those two concepts were the magnitude and the direction of a vector. To model the localization phenomenon, a vector is multiplied by a large number (usually 5,000,000) $2 \times 2$ matrices each of which contain a random element. For a layered optical system this would represent a layer thickness which is randomized. As the vector is multiplied by these random matrices the vector's magnitude grows and the rate of that growth (divide the natural log of that magnitude by the number of matrices multiplied) gives the intensity of the localization phenomenon. This aspect was almost the sole focus of the student's effort during the summer.

At the beginning, the issues were first explained to the student in the context of the simplest system where localization arises, an infinitely long mass-spring chain where the masses are random. Once the student was comfortable with this problem and had reproduced results using already existing MATLAB code, more advanced work was pursued.

There are very few localization type results where the answer is known analytically upfront. Fortunately, there is one problem, the random Fibonacci sequence, for which an answer is known, and which is modeled exactly like a localization problem. As a result, the student worked extensively comparing the results of the MATLAB code developed to see how closely it could match the known random Fibonacci sequence result as various parameters were varied.

Over a month into the summer 2009 research, the student had developed enough MATLAB skill and understanding of the sequence code to begin modifying code so that averaging of results could be built into the code. In other words, after doing a run of 5,000,000 random matrix multiplications, the code would do subsequent runs of 5,000,000 matrix multiplications and average those results. No previous published results were available for such an approach, so the student's work in this area was crucial in determining how many averages made sense, and assisted in generating similar results for optical localization. From the student's perspective, he was now much better prepared for his first "introduction to engineering" course, in which MATLAB was taught.

The fall 2009 session was devoted to continuing simulations of the random Fibonacci sequence. The faculty mentor met weekly with the student, and new results were obtained, even though much less time was spent by both the student and professor on the research compared to the summer. For spring and summer 2010, the student will be working on enhanced graphical 
displays of the localization results and he will be more actively involved generating optical localization results for optically layered systems not previously studied.

\section{Supply Chain Security}

Before September 11, 2001, security at US ports was primarily focused on access control, detection of stolen products, narcotics, and illegal aliens, and protection of personnel, infrastructure, and cargo. Right after September 11, 2001, in an effort to protect the US homeland from another deadly and destructive terror attack, the US Government implemented, through various law enforcement agencies, several security initiatives. For instance, the US Customs and Border Protection implemented the Container Security Initiative (CSI) and the Customs Trade Partnership Against Terror (C-TPAT), the US Coast Guard implemented not long ago an underwater port security initiative that is still in the early stages, and the Department of Energy implemented the Megaports initiative. All of them with the same goal: to better secure the US homeland and to facilitate trade and commerce.

Even though the progress achieved to date in the US in terms of homeland and supply chain security is remarkable there are some areas that need more attention as the probability of another terror attack is always greater than zero. One of such areas is underwater port security.

In this project, the student is focused on:

- Reviewing the existing literature and technology on port security with special focus on underwater security.

- Understanding the challenges, goals, priorities, and supply chain and port security initiatives launched by the US Department of Homeland Security.

- Identifying gaps that need to be filled in and issues that need to be addressed to better secure the underwater space of US ports.

- Developing tools and methods at the conceptual level to improve underwater security at US ports.

The 5-year plan student involved in this project had an interesting background. He has relevant military experience as he used to be part of the US Air Force. His military experience allows him to understand well the challenges associated to homeland security and supply chain security. However, what makes him a valuable asset to the program is his passion for serving his country. That passion will be the fuel that will energize him to overcome the obstacles that he will find and will be his source of inspiration to succeed facing the challenges that he will face.

The student spent most of the summer reading various articles on supply chain security and learning about relevant subjects such as Risk Analysis and Industrial Safety. Learning about Risk Analysis and Industrial Safety provided the student with scientific background to formally model the supply chain security problem which is essential to get the attention of the scientific community. Other sources of information for the student were videos on previous maritime security conferences that the student downloaded from Internet and conversations that he had with his advisor who has published articles on supply chain security. Watching videos of prestigious maritime security conferences provided the student with valuable insight and key 
domain knowledge to better understand the major challenges in the domain of supply chain security which is essential to continue moving forward and make a relevant contribution to the field.

From day one in the 8-week summer program the student was required to document the findings of his research. The logic behind documenting the findings of his research was twofold. First, it was important to start creating a database of both the findings of the research being conducted and the knowledge being generated. Second, the document prepared by the student will be the basis of an article that will be submitted to a peer-reviewed journal.

In spite of the student's military experience significant learning took place during summer. At some point during the summer the student identified underwater port security as the area in which he would like to focus. He argued that due to its relevance and limited advancement compared to other areas in supply chain security it was worth investigating and making a meaningful contribution in the domain of underwater port security.

Unlike the other three projects reported in this paper in which the students had access to handson experiences through different means, for instance MATLAB, this student was able to acquire hands-on experience through the multiple security conferences that he attended "virtually" via video clips that he downloaded from Internet. These national security conferences proved to be valuable experiences for the student as he had a chance to learn about the challenges, threats, and opportunities in supply chain security that built upon his military experience. The fact that he identified underwater port security as the area that he would like to research in order to make a contribution to his country reflects the impact those national security conferences have had on his research.

The goals for the fall semester were rather simple: continued learning about underwater technology for port security and continued documentation of both the findings of the research being conducted and the knowledge being generated. For the most part the goals for the fall were achieved.

For the spring and next summer, the student will:

- Continue learning about underwater technology for port security

- Continue documenting both the findings of the research being conducted and the knowledge being generated

- Finish article on underwater port security

- Submit article to a peer-reviewed journal

- Present research in a conference on maritime / port security

\section{Small and Community Wind Power}

As the United States faces one of the worst energy crises in its history, the government has been willing to step in and fund alternative energy projects and states have begun to write legislation for Renewable Energy Standards that will provide goals to attain a certain percentage of renewable energy per state. Tax incentives, available to those willing to invest in small wind 
systems, create conditions favorable to get homeowners and communities involved in small wind projects. However, the decision making process to facilitate the growth of small wind projects requires background knowledge regarding where to locate a turbine, how much it will cost, how much maintenance it will require, and if the system will be profitable. Such knowledge can be attained through Decision Support Systems that link to databases and retrieves vital wind speed data, wind density, tax incentives, and wind turbine comparisons specific to each site. Data can then be processed into a user friendly format to provide homeowners and communities with the knowledge they need to begin such a venture.

The student associated with this project is developing a Decision Support System (i.e., an expert system) with the characteristics and features just described. The Decision Support System (DSS) facilitates decision making by providing advice on fundamental design and operational aspects of small wind systems. The long-term vision for this project includes developing a DSS for other regions in the world, for instance Latin America, where there is a considerable demand of computer-based tools that can be used to enhance and facilitate the decision making process in regions where limited progress has been made in areas such as the small and community wind. Materializing this idea will require customizing the DSS to the economy and language of the country in question (e.g., Mexico, Costa Rica, Panama, Colombia, etc.).

Another application of the DSS in question is education as the DSS can be used in K-12 schools as well as in universities, at undergraduate and graduate levels, to teach students fundamental principals in the wind industry. The functionality of the DSS allows for the development of business cases to design and operate small and community wind farms. After the student enters data pertinent to the geographic point in question the DSS can serve as a financial or maintenance advisor reporting key indicators (e.g., ROI, payback period) or recommending a plan of action to maintain the wind turbine operational.

At the start of the program the student had some background on the wind industry in general from courses he took in high school and from reading independently articles related to the installation of wind farms in Indiana. However, what makes a difference in his case are his ability to work with numbers, his advanced analytical and problem solving skills and his interest, knowledge, and experience in computer programming. In addition to that, the student is able to work hard in an independent way which reflects his motivation. In projects of this nature creativity is a critical and to date the student has delivered creative work.

The student spent the first part of the summer reading material about the wind industry worldwide and eventually focused his attention on small and community wind projects. Through this learning process he developed a solid understanding of the wind industry especially in the area of his interest (small and community wind). The extensive literature review he conducted allowed him to realize that no Decision Support System (i.e., expert system) had been developed to support decision making during the design, construction, and operation of small and community wind turbines which represented an opportunity to make a relevant contribution to the field.

Sometime in the middle of the summer the student advised his mentor about his plan of developing an expert system to be used by communities (e.g., farmers) to design, build, and 
operate small wind turbines. In order to materialize that plan, the student spent some time evaluating various computer programming languages. Microsoft Visual Basic was eventually selected by the student after a detailed evaluation of several computer programming languages. It was a smart decision as before the end of the summer the student was able to have a working demo that he uses since then to illustrate the usability of a computer-based tool that supports decision making during the design, construction, and operation of small and community wind farms.

The student was required to document the work he accomplished during the summer including details of the work done programming the expert system. The plan is: 1) To use the document prepared by the student as the basis of an article that will be submitted to a peer-reviewed journal and 2) To present the expert system in a prestigious conference such as the annual conference of the American Wind Energy Association.

After the completion of the summer program and before the start of the fall semester the student attended the Indiana Wind Conference which included a tour of wind farms located in NW Indiana. The progress made by the student over the summer was remarkable. He now has a solid understanding of the wind industry worldwide and has a clear vision of the challenges and opportunities associated to small and community wind projects. He developed in Microsoft Visual Basic a working demo of an expert system that can be used to facilitate the design, construction, and operation of small wind turbines. He identified conferences at which he can present his research. He started working on an article that will be submitted to a peer-reviewed journal.

He made successful progress over the fall semester:

- Continued searching the literature to identify computer-based tools to support decision making in small and community wind projects in order to borrow ideas that can be implemented in the student's expert system to increase its usability

- Continued working on the expert system to add more functions

- Continued working on the research paper

- Submitted a proposal to the American Wind Industry Association to present his research at the 2010 national conference

Plans for the spring and summer:

- Continue searching the literature to identify new ideas / contributions to the field especially those related to small and community wind turbines

- Continue working on the expert system

- Continue working on the research paper

- Present research at the 2010 international conference of the Latin American Wind Energy Association.

\section{Observations}

All four of the engineering students involved in the first summer of our early undergraduate research program are still committed to completing their engineering degrees at our university. This is not too surprising in that they were volunteers for the program, but anecdotal 
observations from faculty members other than their mentors indicate that these students are more motivated to learn about engineering than their average peers. All four of these students are achieving academic success in their engineering courses. Each of them took at least one engineering course in the fall and there were no engineering grades less than 3.0 on a $4.0 \mathrm{GPA}$ scale. Three of the four students were in the same section of engineering statics in the fall. Their average GPA for the course was 3.5, the average GPA for the course as a whole was 2.9, a substantial difference.

Not all of the students fared as well in their non-engineering courses, however. Both of the students on the 5-year plan for graduation are now a little short of 2.75 cumulative GPA requirement to continue the research with stipend for the second summer. It is within their grasp to get their GPAs back on track by the close of the spring semester and they both seem committed to do so. If they fail to do so, they will have the option of continuing their research, but without stipend/room \& board for the 8-week summer term.

Two additional engineering faculty members have made the commitment to participate in the early undergraduate research program for the summer of 2010. It is expected that at least four and possibly up to six of our current freshmen will be given the opportunity to participate in this valuable program starting this May. The program is funded through summer of 2013.

Participants will be tracked in not only how they do as undergraduates, but what paths they chose after graduation.

Sustainability of the program beyond 2013 may require some creativity. Although we have achieved some initial successes, there is a significant financial and manpower commitment to pull off this program. Annual budget for the program as structured is roughly $\$ 175 \mathrm{~K}$ (for 36 students, 18 first year and 18 second year). A possible way of funding a scaled down version of the program would be through industry financing. We are located in an industrial region and have the support of our local industries. A downside to this approach could be that the research would probably be focused to solving problems within these companies instead of topics generated by faculty member interest.

An approach that may be more feasible would be to place more emphasis on students taking part in directed research during the normal academic year. This would require funding for release time of faculty interested in participating in the program, but would not necessarily require summer stipends. It would take the students a longer time to make meaningful contributions to research since they would not have the benefit of a focused 8-week summer term, but such an approach would still expose them to hands-on research which may increase their interest in completing their studies in engineering.

In any case, we view our initial results 8 months into the program as positive. The students involved remain highly motivated to continue their engineering educations, are more engaged in the classroom, and have achieved better results in their engineering classes than their peers. 


\section{References}

1. B. F. Spencer Jr., S. J. Dyke, H. S. Deoskar. "Benchmark Problems in Structural Control - Part I: Active Mass Driver System." Earthquake Engineering and Structural Dynamics, 1998: 11271139.

2. K. D. Pham, G. Jin, M. K. Sain, B. F. Spencer, Jr., and S. R. Liberty. "Generalized LQG

Techniques for the Wind Benchmark Problem." Special Issue of ASCE Journal of Engineering Mechanics on the Structural Control Benchmark Problem, 2004. 